\title{
Italian Banks' Paths through the Crisis
}

\author{
Stefano Zedda \\ Department of Business and Economics, University of Cagliari, Cagliari, Italy \\ Email: szedda@unica.it
}

Received 3 February 2016; accepted 14 March 2016; published 17 March 2016

Copyright (C) 2016 by author and Scientific Research Publishing Inc.

This work is licensed under the Creative Commons Attribution International License (CC BY). http://creativecommons.org/licenses/by/4.0/

(c) (i) Open Access

\begin{abstract}
Over the past seven years, the financial system has undergone an unprecedented crisis, which has caused important changes in the structure and business models of banks. This paper explores the main changes in the structure of Italian banks' assets in 2007-2013, by size and category, as a result of the financial crisis and of regulatory and business models changes. The analysis shows that the effects of the crisis were very different on different categories, and that business models have changed, pushing the different banking categories to business models and balances increasingly similar.
\end{abstract}

\section{Keywords}

Banking, Financial Crisis, Italy, Business Models

\section{Introduction}

During the last seven years the global financial crisis has had a complex evolution and banking systems had to cope with instability, risks and defaults. Diverse components determined instability: low real economy growth, low bank capitalization, inappropriate use of derivatives and securities, and more.

Banks had to cope with a mix of causes, related to the weakness of the economic systems, both internal and external, low growth and high public debts, and the presence within banks assets of low liquidity bonds and bad loans.

Possible defaults of systemically important financial institutions induced government interventions (State aid), which caused deterioration of public finances and, as a consequence, a second wave of banking problems. As explained in [1], bank business models are not static and evolve over time, and are under the influence of a complex mix of exogenous and endogenous pressures: the structural evolution of the financial system and financial markets; the macro-economic environment in which banks and their customers operate; regulation; the competitive environment in banking markets; financial innovation, and the chosen business objectives of banks.

Within Europe the crisis has had different aspects, in some cases linked to housing bubbles, in other cases to derivatives exposure, or to the interbank freezing, or to sovereign bonds, or to the weakness of the real economy 
(see [2]).

The aim of this paper is to explore the main changes and the accounting dynamics occurred in the Italian banking system over the period 2007-2013 as consequence of both the financial crisis and the evolution of banking regulation and business models.

The Italian banking system "does not speak English", as it is mostly linked to a traditional banking activity, with loans representing an important share of total assets. For this reason the impact of the sovereign crisis of 2011 was stronger than the 2008 global financial crisis, which was mostly linked to structured financial instruments in banks' balance sheets. In fact, as reported in [3], the capital and liquidity positions of Italian banks, as well as their profitability, experienced little deterioration during the first phase of the crisis between July 2007 and September 2008.

Before developing the analysis of Italian banks by category, for having a reference framework, some paragraphs are devoted to the evolution of the crisis and regulation in Europe.

The rest of the paper is structured as follows: Section 2 presents the regulatory framework evolution; Section 3 describes the Italian credit system as a whole; Section 4 analyzes the evolution of the assets composition by dimensional categories; Section 5 compares the paths of Italian banks dimensional categories and Section 6 concludes.

\section{Regulatory Framework Evolution}

The financial turmoil and the subsequent regulatory response caused significant changes in the European banking system, which evolved in terms of capitalization, leverage, profitability, portfolios loans quality, concentration. EU banks show an increasing trend in the level of capital, notwithstanding the challenging conditions in financial markets. Nonetheless, the continued deterioration of both the quality of banks' loan portfolios and profitability may also pose challenges in some cases to the maintenance of adequate capital levels.

What we learned from the financial crisis is that the banking sector must have the ability to absorb shocks occurring at micro and macro level. This means that if something goes wrong (in financial markets, in the real economy, in public finances), the bank must have a sufficient amount of capital to cover its losses.

A confirmation of the fundamental role of the capital coverage is also in [4], which evaluates the explicative power of balance sheet variables for measuring the default probabilities of banks, shows that the traditional CAMELS variables have different roles in different countries, apart from the TIER1 ratio that is the only one resulting always significant.

In this respect, our starting point is the analysis of the capital ratio of banks.

The global financial turmoil opened important debates on the size of financial systems, the structure of financial institutions, the costs and benefits of financial innovations and the role of government and regulation. Since the financial crisis erupted in 2007 many regulatory reforms have been implemented and are under discussion. The European Commission pursued a number of initiatives to create a safer and sounder financial sector for the single market. These initiatives form a single rulebook for all financial actors in the 28 Member States of the European Union that is the foundation on which the Banking Union sits. The EU institutions agreed to establish a Single Supervisory Mechanism and a Single Resolution Mechanism for banks. The new regulatory framework contains the Capital Requirement Directive (CRD IV) and Regulation, through which Basel III will be implemented in Europe. Basel III regulatory standards were agreed upon the 27 members of the Basel Committee for Banking Supervision with the objective to strengthen the quality, consistency and transparency of the capital base. In terms of banking activities, two reports were published with proposals on activity restrictions: the Vickers report in the UK and the Liikanen report in Europe. As part of a continued effort to restore confidence in the EU banking sector and ensure resilience of the banking system, the EBA coordinates the Asset Quality Review and the Stress Test for all EU countries with the guidance of ECB. The comprehensive assessment-which joined up the AQR and the stress test components-was aimed at strengthening banks' balance sheets, enhancing transparency and building confidence.

The capital ratio was the core of the Basel I framework agreed in 1988 which set the proportion capital to risk weighted assets to $8 \%$.

Basel II has enhanced this approach fixing a more specific capital coverage, which requires the bank to quantify the risk of each single loan. As a consequence, when the more recent evolution suggested to pay more atten-

${ }^{1}$ As defined by G. Tremonti, Italian Minster of the Economy and Finance, in 2008. 
tion to banking stability, the Basel III framework required banks to hold more and better capital.

In formal terms "more capital" became higher capitalization parameters, namely in higher minimum capital coverage, obtained as the ratio between Total Regulatory capital (TCR) and Risk Weighted Assets (RWA). Pillar 1 raised the common equity to $4.5 \%$ of the RWA and introduced a capital conservation buffer in the form of additional common equity for $2.5 \%$ of RWA, as well as of a countercyclical buffer requiring a further range of $0 \%$ $2.5 \%$ of common equity. "Better capital" changed the TRC definition, so that parameters deeply changed even without any variation in balance sheet values, and in the large majority of cases this resulted in a lower capitalization parameter. More, the package also includes higher weights for some categories of risk. It also implies a more conservative evaluation (higher weights) for some assets categories (for example certain complex securitizations).

A quantitative impact study developed by the EBA has estimated the effects of the Basel III capital definition changes for European banks (see [5]). Values for Group 1 (larger and internationalized banking groups) and group 2 (smaller banking groups) are reported in Table 1.

In fact, both sides of the new regulation, definitions and minimum parameters, imposed a raise of capital coverage.

Banks can obtain a higher capitalization in different ways ( TRCratio $=\frac{\text { TRC }}{\text { RWA }}$ ): either they can raise the level of regulatory capital (TRC), or they can decrease risk weighted assets. This second strategy can itself be the effect of a reduction of the amount of assets, in a stable risk profile, or a decreasing risk profile given the total assets value.

The actual evolution of the real economy played an important role in this framework, as the European economic crisis, that followed the initial financial crisis, increased the riskiness of the ongoing loans. In this context, possible strategies to accomplish the need of more capital were limited to three possibilities: a deep reduction of the riskiness associated with new loans, a deceleration in the issuance of new loans or a capital rising.

In the following paragraphs we analyze the basic variables for evaluating the different paths that possibly lead to similar results in the diverse areas.

In particular, we split the ratio TRC/RWA in the two components (TRC/TA)*(TA/RWA) that represents, respectively, the capital coverage of the bank activity and the assets safeness. Capital and assets levels are considered in their trends, also considering the impact of income.

The different paths not only depend on the diverse strategies that each bank has chosen with respect to their risk profile, but also on the balance sheet policy.

In fact, a liquidity problem for a loan debtor can induce a rising in credit limit for the debtor, higher risk weighting of the loan, and a higher correction in the expected losses. This results in higher RWA, so to lower TRC/RWA, and reduced impact on income.

But if the bank doesn't allow for this credit flexibility, the loan can result in a default, and the bank will have lower TA, lower RWA, and a loss hitting the income.

\section{Italian Credit System}

For analyzing the effects and behavior in terms of total credit during this period we have to consider the whole credit system.

During the crisis, the tightening of interbank markets and the resulting reduced liquidity, and capital constraints, contributed to a reduction of credit supply (see [6] and [7]).

Figure 1 reports the values of total assets split into its main components, namely loans, government securities, other securities, shares, and other assets.

As evident from the figure above, total assets significantly increased up to 2008. The first part of the crisis

Table 1. Average estimated change in total capital ratio and RWA due to Basel III.

\begin{tabular}{ccc}
\hline & Group 1 & Group 2 \\
\hline Average Tier1 capital ratio as of 30 June 2011 & $11.9 \%$ & $10.9 \%$ \\
Average Tier1 capital ratio under Basel III & $6.7 \%$ & $7.4 \%$ \\
Change in RWA due to Basel III & $21.2 \%$ & $6.9 \%$ \\
\hline
\end{tabular}




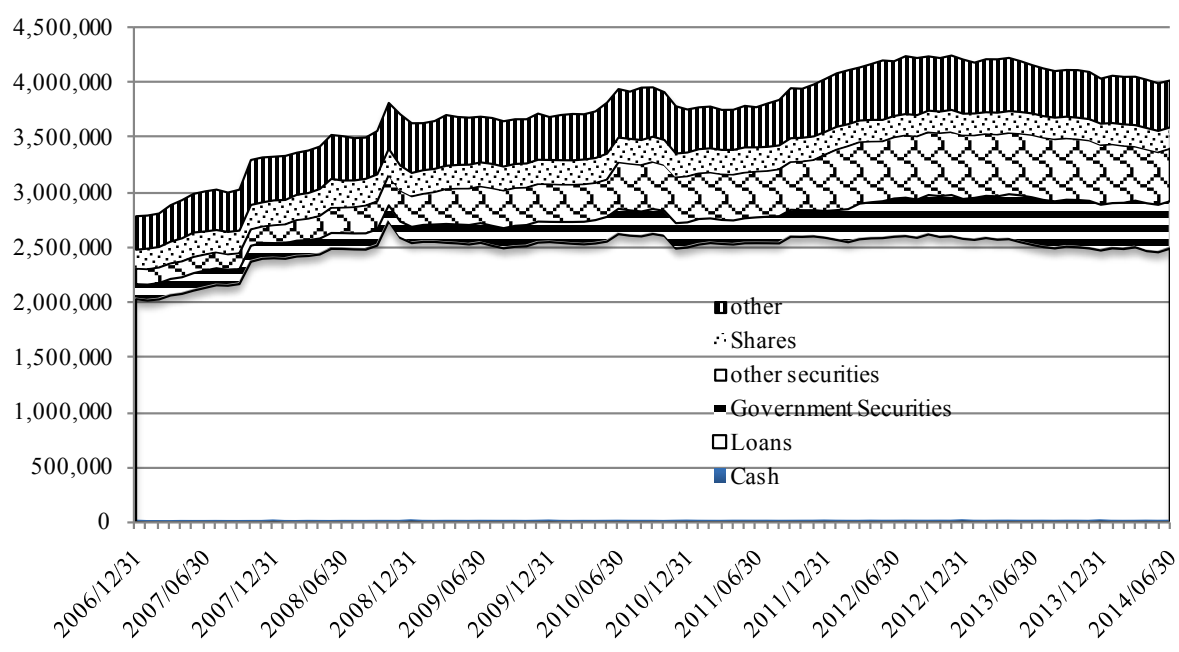

Figure 1. Italian credit system evolution. Source: Banca d'Italia.

caused a stop in this growth, from 2009 to 2012 then a reduction in value from 2012 to 2014. On the contrary, the loans component was quite stable around 2500 billion euro from 2008 on and the securities component — both government and non government securities — expanded during the same period so to reach about 3.4 times its initial value.

Such movements can be explained by at least two components. The first is the drop in the quality of loans, as shown by the almost linear increase in bad loans from 2010 on (no data are available for the previous years), inducing a flight to quality.

The second component is related to funding: as evidenced in [8] with reference to the first part of the crisis (2007-2008), the structure of bank funding plays a critical role in the transmission of shocks. In the subsequent evolution the important reduction in the foreign exposures to Italy induced investing in assets more liquid and/or more rewarding (like government securities, given the high spreads in the period 2010-2012) (Figures 2-4).

\section{Assets Composition Evolution}

The second part is developed analyzing the Italian bank groups by dimension, with a separate grouping of the cooperative banks and other stand alone banks, for verifying if, the same kind of differences observed among European countries can be evidenced also within Italy, so that the differences between different banking categories induced different reactions and evolution of business models. As found in [8], initial banks' balance sheet structure mattered for loan growth once the banks were hit by the crisis.

Data for these analyses come from banks balance sheets and Bankscope (Table 2).

Large banking groups (Total Assets higher than $100 €$ bn.) had a quite slow evolution over the time window 2007-2013. The main changes are related to the pre crisis period (2007-2008) when loans $(+15 \%)$ and derivatives (+97\%) had an important growth rate. The interbank loans dropped from the initial 162 to the 201362 billion euro, while the goodwill had two important reductions in 2011 and 2013, each one halving the previous value (54.9 in 2010, 26.6 in 2011, 12.2 in 2013). Total assets stayed almost stable over the period, just dropped of about $8 \%$ in 2013 mainly due to the reduction in loans and derivatives. Securities had a small, but quite regular growth from 445 of 2007 to 603 billion euro in 2013. The derivatives incidence on total assets ranged from $5 \%$ in 2007 to $9.5 \%$ in 2011 (Figure 5).

Differently from the large banking groups, the medium ones (total assets between 20 and 100 billion euro) had a significant growth in loans up to 2011 ( $+60 \%$ on 2007), when they almost reached $400 €$ bn., to drop then to $356 € \mathrm{bn}$. in 2013. Derivatives doubled in the same period, ranging from $2.3 \%$ of total assets in 2007 to $4.1 \%$ in 2011. Similarly, securities almost doubled from 2008 to 2012 ranging from $13 \%$ of TA in 2008 to $22 \%$ of TA in 2013 (Figure 6).

The evolution of small banking groups (total assets lower than 20 billion euro) is also different from the previous ones, with lending volumes rather stable form 2008 to 2013. The interbank loans fall from 12 billion euro 


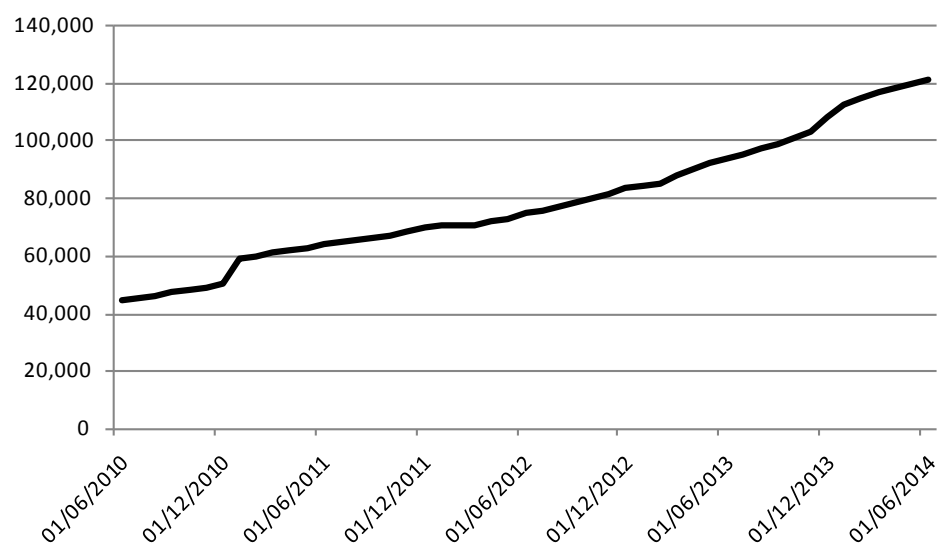

Figure 2. Italian credit system evolution. Source: Banca d'Italia.

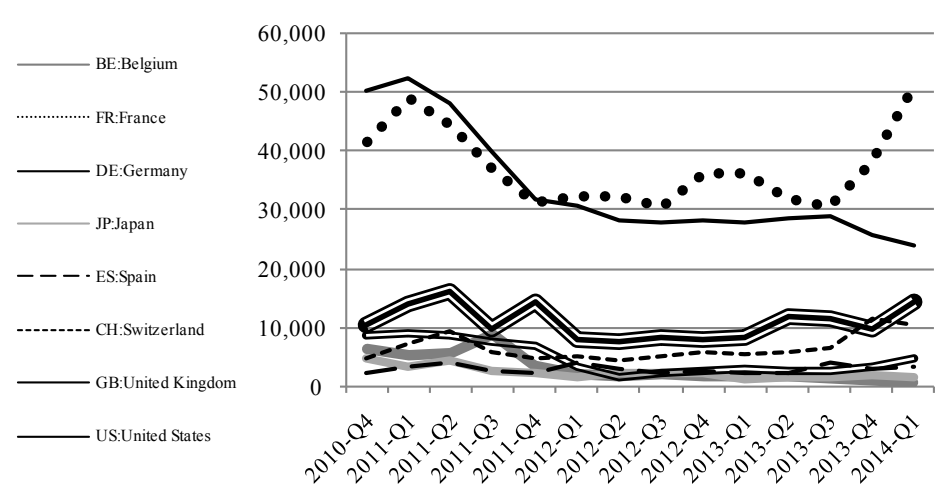

Figure 3. Foreign exposures to Italian banks. Source: BIS.

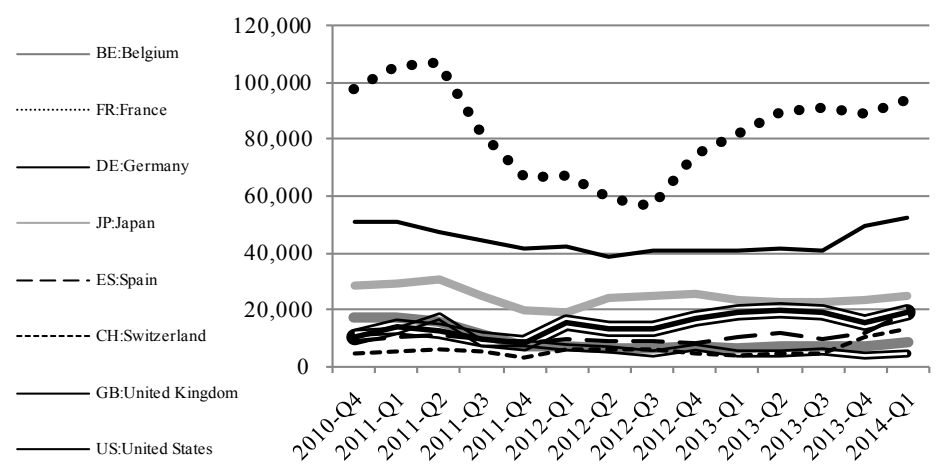

Figure 4. Foreign exposures to Italian public sector. Source: BIS.

Table 2. Sample description. Source: Bankscope.

\begin{tabular}{ccc} 
& $\mathrm{N}^{\circ}$ banks/banking groups & Total assets 2013 (million euro) \\
\hline Larger groups & 5 & $1,921,511$ \\
Medium sized groups & 15 & 662,737 \\
Small groups & 24 & 158,986 \\
Other stand alone banks & 48 & 76,419 \\
BCC & 251 & 158,766 \\
TOTAL & $\mathbf{3 4 3}$ & $\mathbf{2 , 9 7 7 , 4 2 2}$ \\
\hline
\end{tabular}




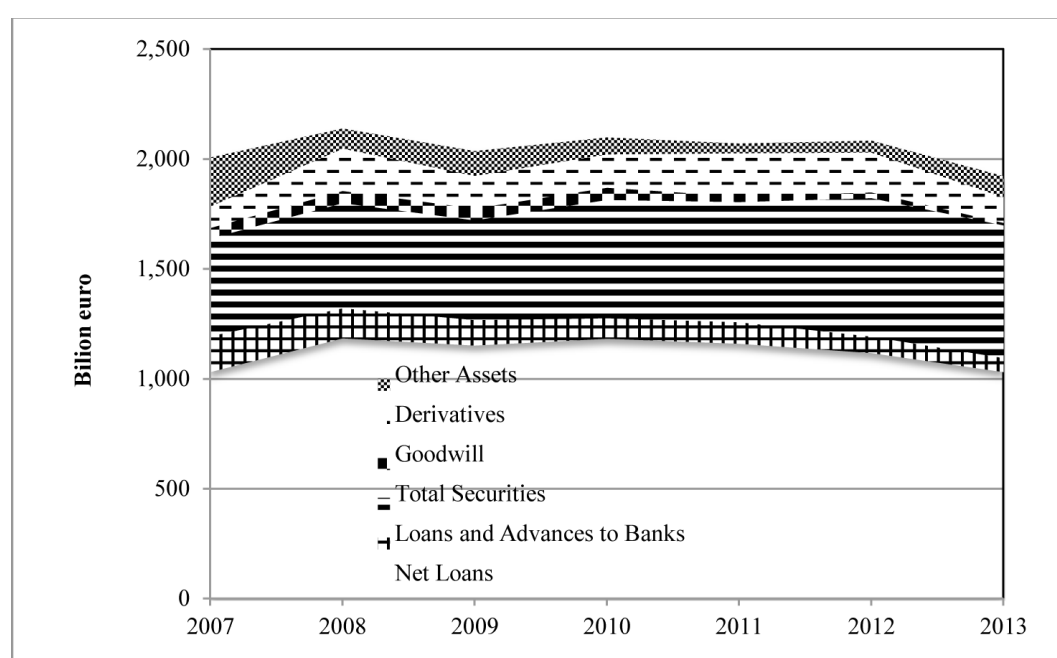

Figure 5. Assets composition, large banking groups.

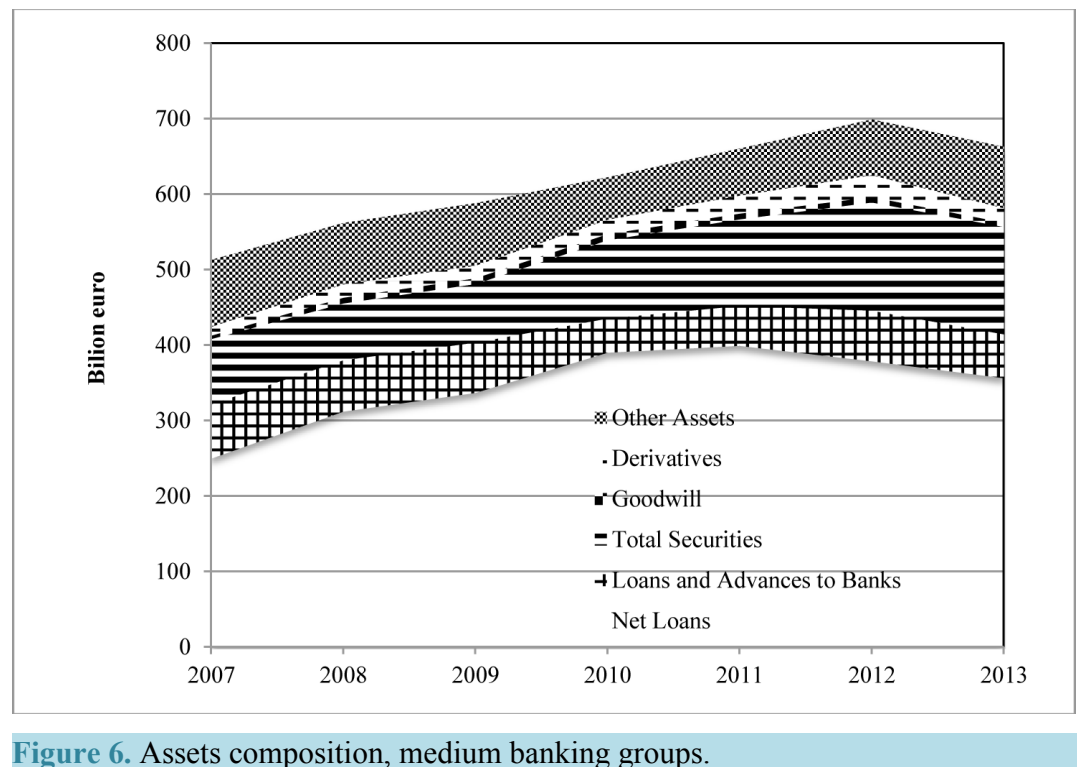

in 2007-2009 to 7 billion euro of 2010-2013.

But the main variation refers to securities, that grow continuously from 2007 to 2011, (+38\%), and even more between 2011 and 2013 almost doubling its relevance, and becoming the main category in the assets expansion, so that the incidence comes from $13 \%$ of 2007 to $30 \%$ of 2013 . Derivatives have a really small incidence, around $1 \%$ of total assets (Figure 7 ).

The other stand-alone banks had an evolution similar to the small groups, even if loans grow up to 2012 and the interbank lending is stable over the considered time span. Even these banks raised their securities share in the last two years, coming from $12 \%$ of 2011 to $22 \%$ of 2013 . Here also really small the derivatives incidence, always lower than $1 \%$ (Figure 8 ).

The cooperative banks (BCC in Italian) are the smallest banks within the considered categories, with an average of 632 billion euro of total assets. These banks keep a loans volume almost stable up to 2011 (with incidence higher than 70\%) but then changed their behavior increasingly investing in securities. In the last two years considered securities not only had a deep growth (almost doubling its value), but this way they reduced the volume of loans.

More, between 2007 and 2013 the interbank lending doubled, coming from 5.6 to 10.6 billion euro.

Here also the derivatives are irrelevant (Figure 9). 


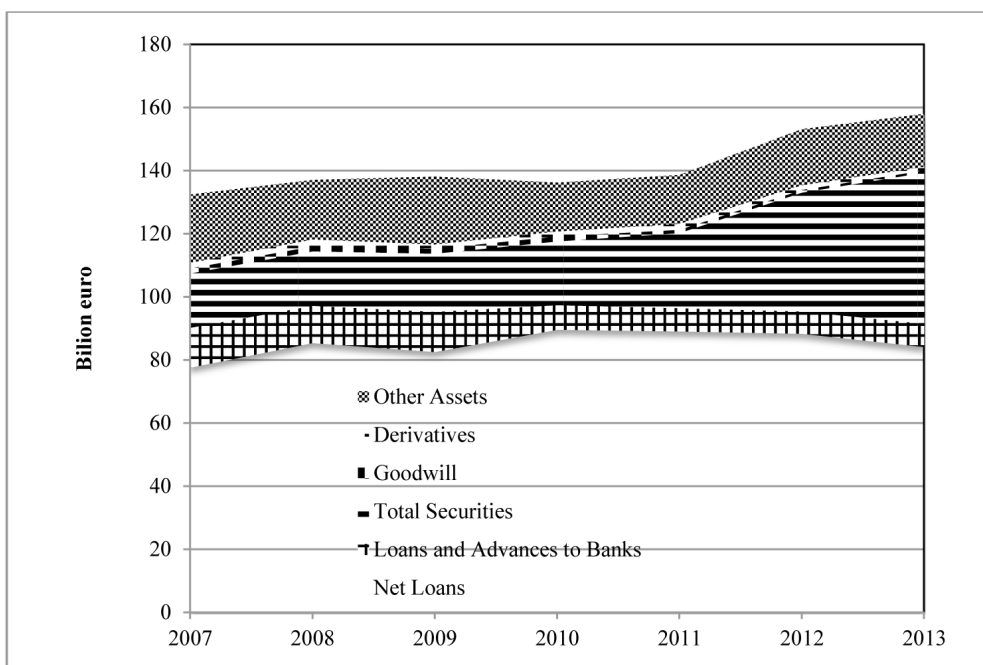

Figure 7. Assets composition, small banking groups.

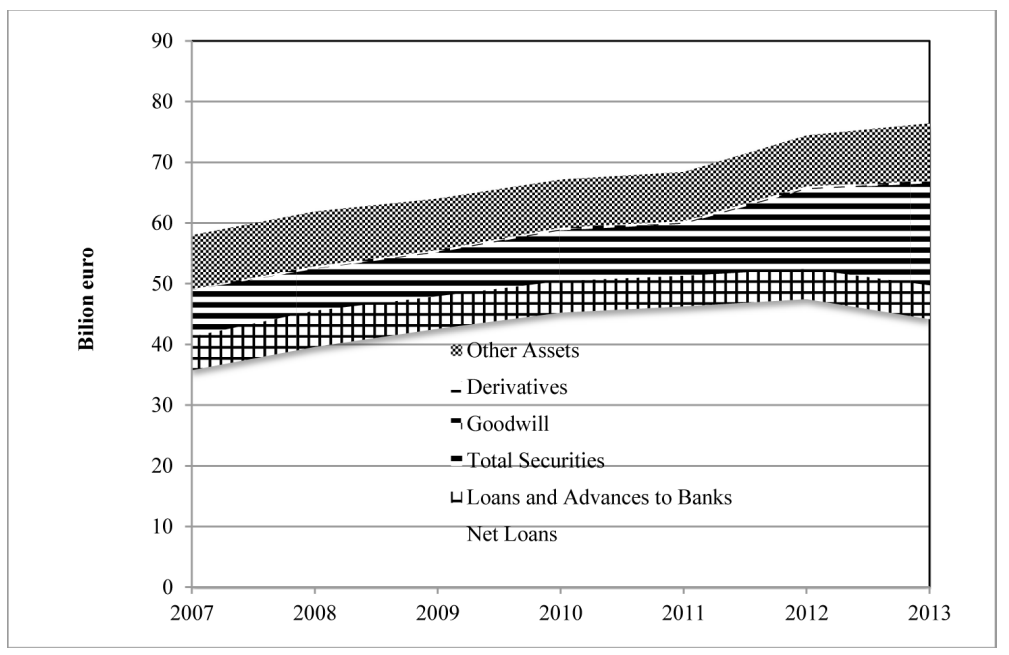

Figure 8. Assets composition, other stand-alone banks.

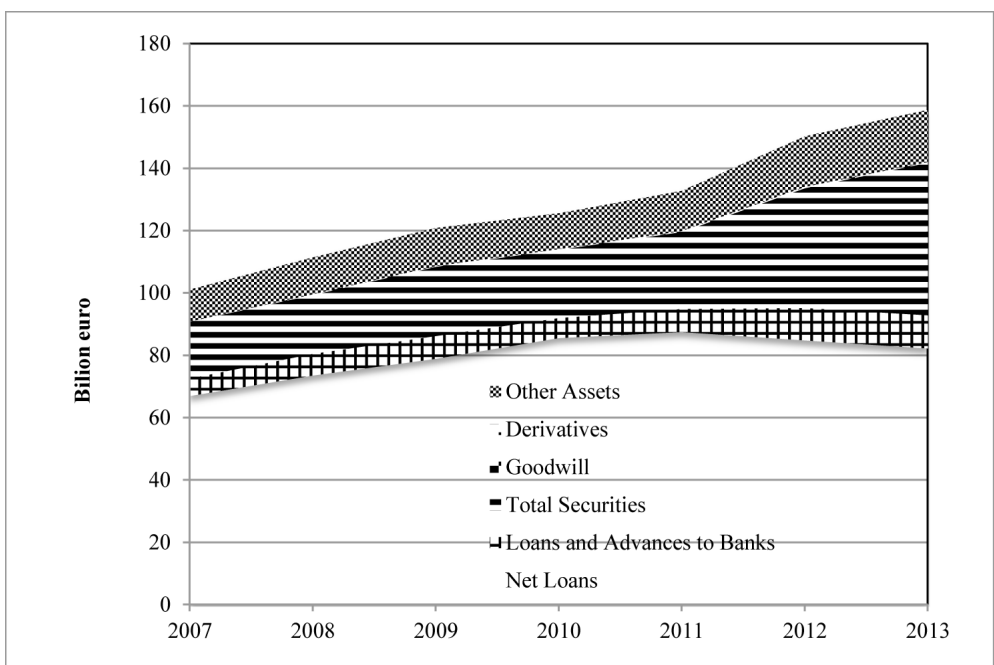

Figure 9. Assets composition, BCC banks. 


\section{Italian Banks Paths}

The share of liquid assets also shows different paths for the different groups, but a convergence to lower and increasingly similar values, ranging in 2013 from $9 \%$ to $13 \%$ (Figure 10).

Referring to the assets safeness (as proxied by the TA/RWA in Figure 11), the crisis effects had diversified impacts on different banking group sizes.

The 2008 crisis had a higher impact on small banking groups, which lowered their assets safeness before starting an important recovery during the following years. Large groups instead had a relevant impact of the 2011 sovereign crisis, which lowered the value below the trend, but not sufficiently for an actual reduction below the previous year value. Despite its small dimension, the $\mathrm{BCC}$ were not destabilized by both crises, but were capable of smoothing these effects and, except from 2008, went on a homogeneous safeness rising, in line with the whole national system.

On the other side, the direct "capital over assets" ratio shows a general tendency to the reduction in capital coverage, mainly due to a raising in assets value (16\%) higher than the one in capital value (10\%). Also in this case the trends are convergent (Figure 12).

Considering the Return on Assets (ROA, Figure 13) we can see the different effects the two crises induced on different banking sizes: as the 2008 crisis affected more seriously the small groups, the 2011 crisis hugely hit the large banking groups, that form 2009 to 2013 constantly obtained the lower returns.

The effects of income in capitalization are not always direct: as the effect of the 2008 is still visible for the smaller banks, the same is not evident for the 2011 crisis, where the important losses effects for the large groups are not visible in terms of capitalization that raised during this year.

Instead, it is evident the convergence of TRC/TWA, that comes from an initial ranging of 11 percent points (from $9.4 \%$ of medium sized groups to $20.5 \%$ of BCC), to a range of about 4 percent points, from $13.4 \%$ of medium sized groups to $17.6 \%$ of BCC (Figure 14).

The final effect of assets PD, return and capitalization can be read in terms of bank estimated PD, computed on the base of the methodology in [9], is reported in Figure 15.

In this graph is evident that the smaller banks were seriously hit in the 2008 crisis, while the reactions of the medium and large groups, starting from higher values, were prompt and effective in lowering the bank default risk.

\section{Conclusions}

The Italian banking system has had to react to important effects of the recent crisis. Contagion effects, higher riskiness of loans, instability of sovereign bonds were the most relevant.

The main evidence in this analysis is that the impacts and effects of the crisis were substantially different among different banking dimensions and structures. The large groups were mainly hit by the 2011 sovereign crisis, while the smaller ones were mostly exposed to the 2008 crisis.

During these years the business models had changed, so to react to the framework evolution: lower risk exposures, and higher capital coverage prevented the system from excessive impacts on banking stability.

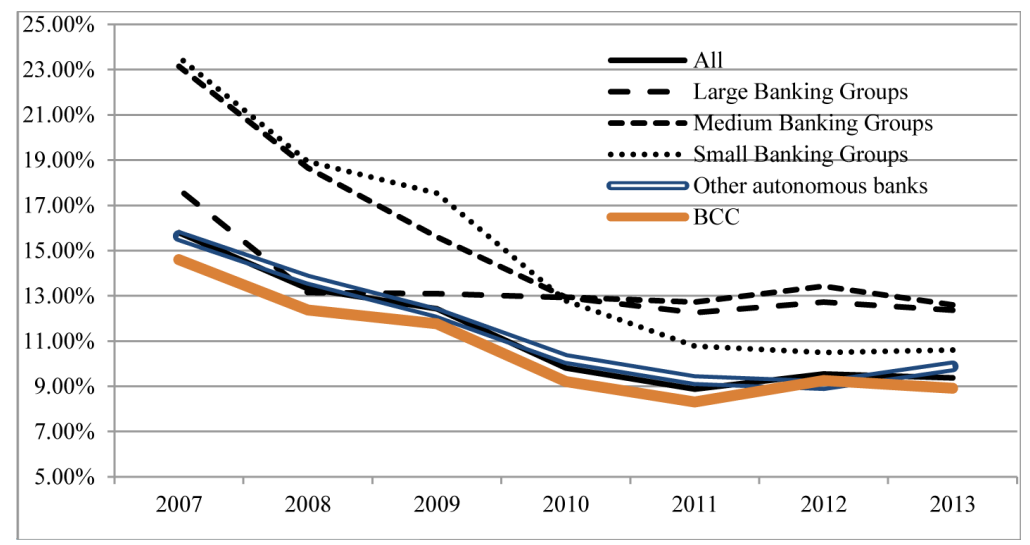

Figure 10. Liquid assets/Total assets. 


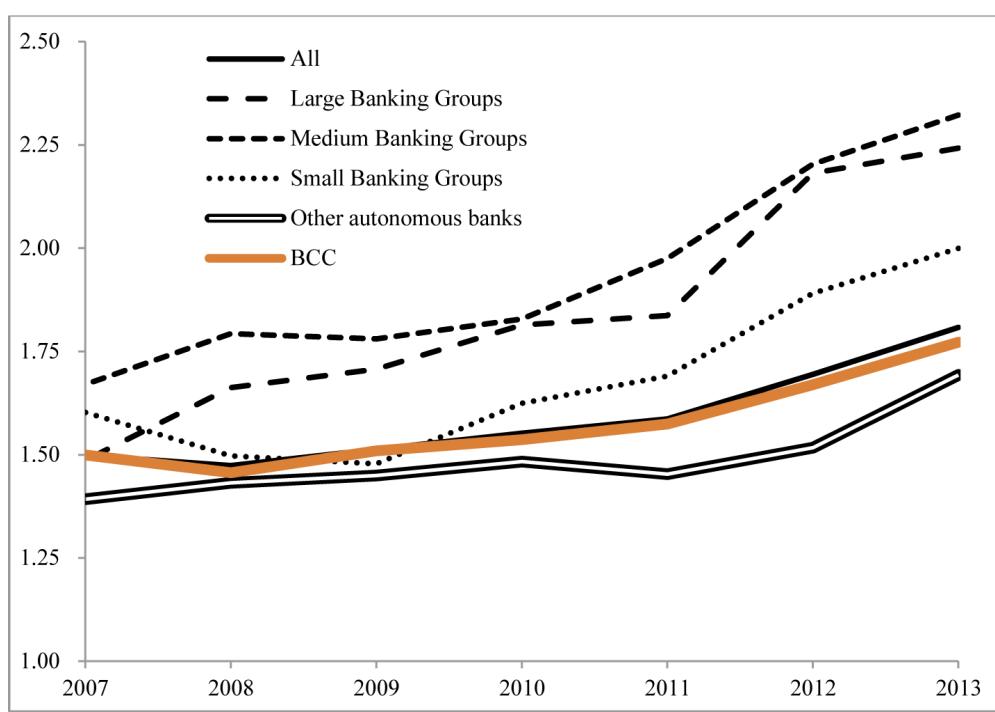

Figure 11. Total assets/Risk weighted assets.

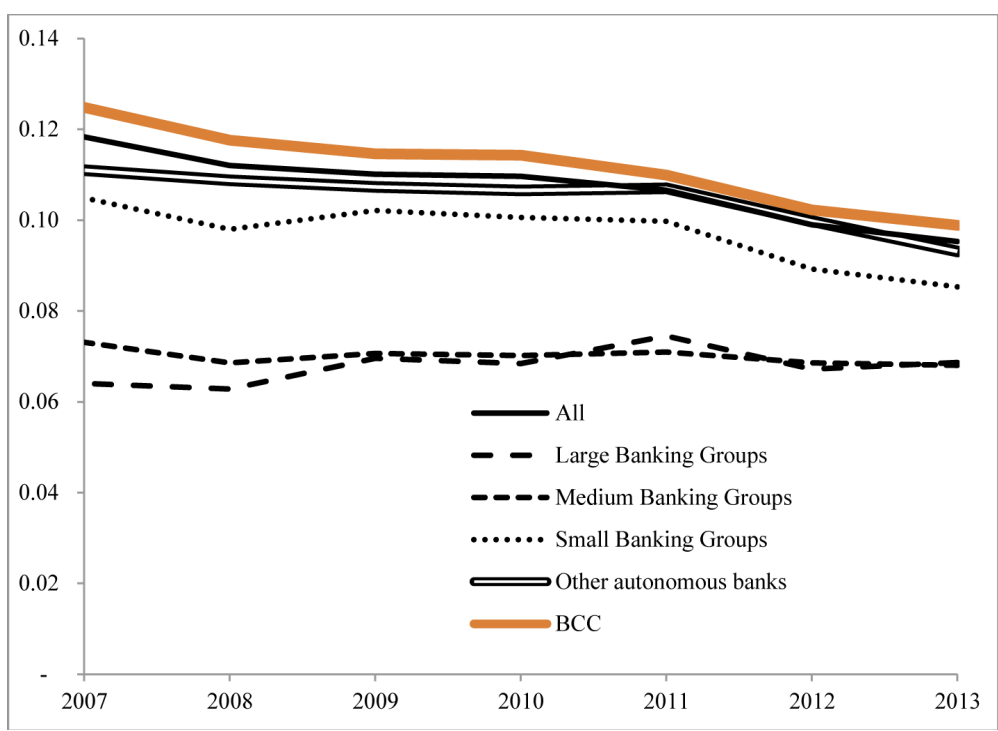

Figure 12. Total regulatory Capital/Total assets.

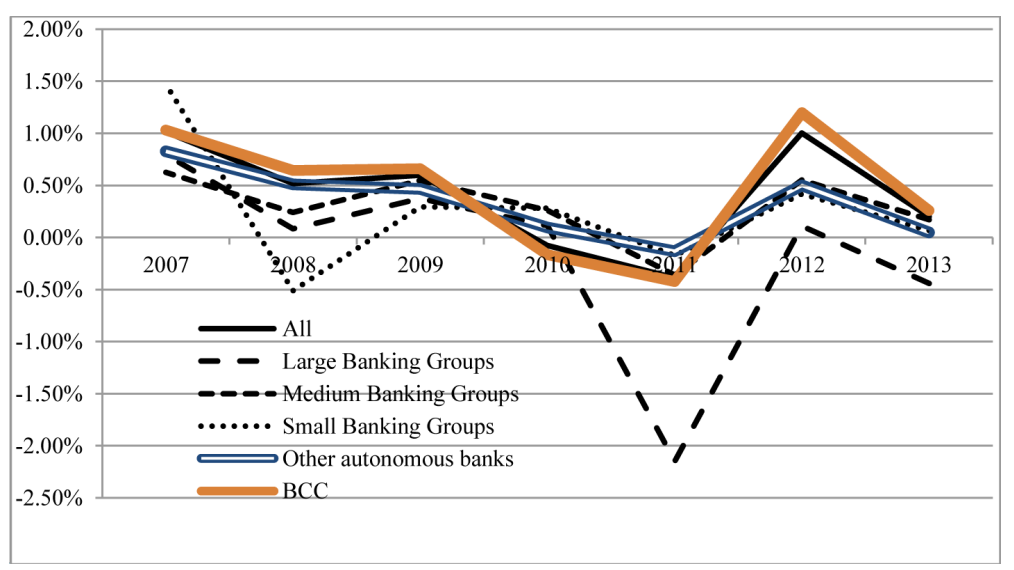

Figure 13. Return on assets. 


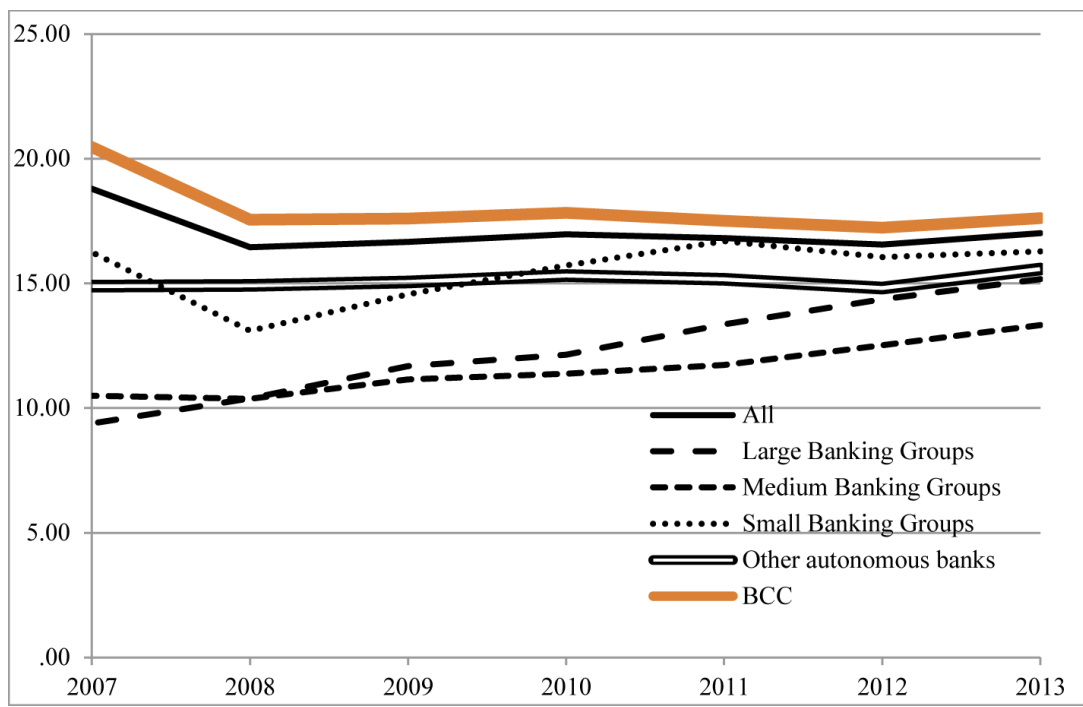

Figure 14. Total regulatory Capital ratio.

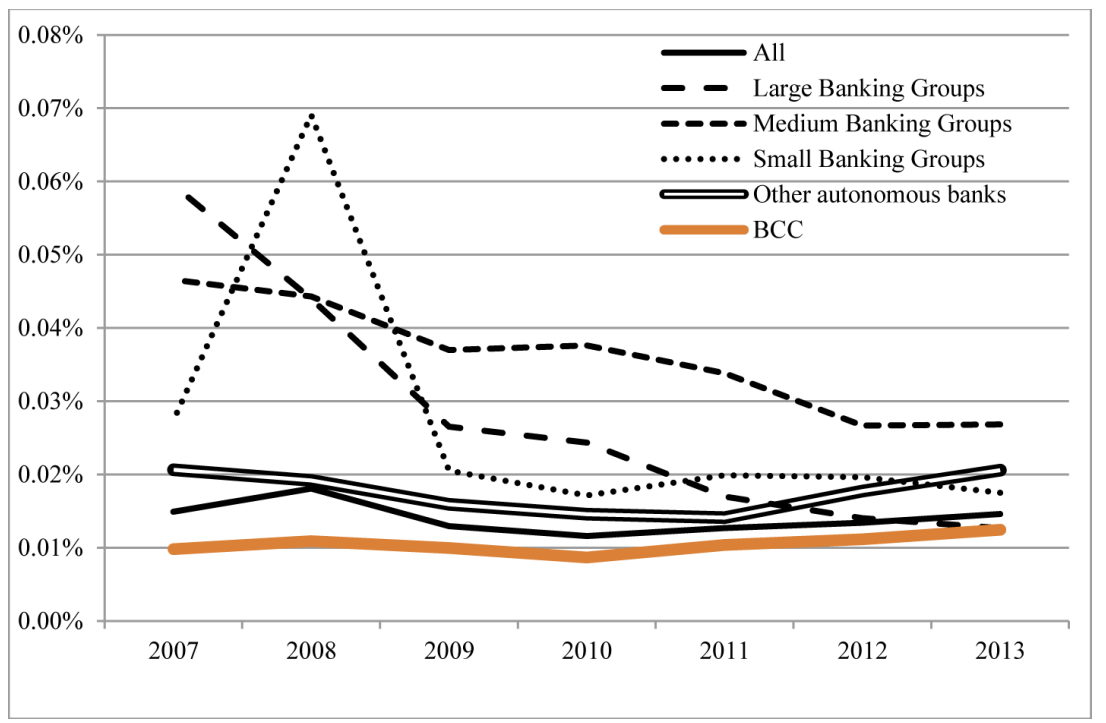

Figure 15. Bank estimated probability to default.

This resulted in a reduction in value and higher selection in new loans issuing, raising the banking stability but reducing the positive sustain to the real economy.

This evolution has, indeed, reduced the former diversification of the Italian banking system, so that the diverse components are moving to more and more similar business models.

\section{References}

[1] Llewellyn, D.T. (2012) The Evolution of Bank Business Models: Pre- and Post-Crisis. Future Risks and Fragilities for Financial Stability, SUERF: Study, Wien, March 2012, 45-67.

[2] Beck, T. (2014) Finance, Growth, and Stability: Lessons from the Crisis. Journal of Financial Stability, 10, 1-6. http://dx.doi.org/10.1016/j.jfs.2013.12.006

[3] Presbitero, A.F., Udell, G.F. and Zazzaro, A. (2014) The Home Bias and the Credit Crunch: A Regional Perspective. Journal of Money, Credit and Banking, 46, 53-85.

[4] Altman, E.I., Cizel, J. and Rijken, H.A. (2014) Anatomy of Bank Distress: The Information Content of Accounting Fundamentals within and across Countries. http://ssrn.com/abstract=2504926 
[5] European Banking Authority (2011) Quantitative Impact Study.

[6] Del Giovane, P., Eramo, G. and Nobili, A. (2010) Disentangling Demand and Supply in Credit Developments: A Survey-Based Analysis for Italy. Journal of Banking and Finance, 35, 2719-2732.

[7] Panetta, F. and Signoretti, F. (2010) Domanda e offerta di credito in Italia durante la crisifinanziaria. Bank of Italy, Occasional Papers, No. 63.

[8] di Patti, E.B. and Sette, E. (2012) Bank Balance Sheets and the Transmission of Financial Shocks to Borrowers: Evidence from the 2007-2008 Crisis. Bank of Italy, Temi di Discussione (Working Papers), No. 848.

[9] Zedda, S., Cariboni, J., Marchesi, M., Giudici, M.P. and Salto, M. (2012) The EU Sovereign Debt Crisis: Potential Effects on EU Banking Systems and Policy Options. European Commission: Scientific and Technical Research Series, Publications Office of the European Union, Luxembourg. 